\title{
Electric and magnetic field variations arising from the seismic dynamo effect for aftershocks of the M7.1 earthquake of 26 May 2003 off Miyagi Prefecture, NE Japan
}

\author{
Naoto Ujihara ${ }^{1}$, Yoshimori Honkura ${ }^{1}$, and Yasuo Ogawa ${ }^{2}$ \\ ${ }^{1}$ Department of Earth and Planetary Sciences, Tokyo Institute of Technology, Tokyo, Japan \\ ${ }^{2}$ Volcanic Fluid Research Center, Tokyo Institute of Technology, Tokyo, Japan \\ (Received October 5, 2003; Revised January 24, 2004; Accepted January 28, 2004)
}

\begin{abstract}
Some examples of electric and magnetic field variations have recently been reported by Honkura and his colleagues in association with earthquakes, and these variations have been interpreted by them in terms of the seismic dynamo effect. In order to confirm that this effect is a universal phenomenon rather than a phenomenon appearing in a special local condition, we made magnetotelluric (MT) observations above the hypocentral area of the M7.1 earthquake which occurred off Miyagi Prefecture, northeastern Japan, on May 26, 2003. The MT site was selected at a location close to a seismic station belonging to the nation-wide seismic observation network called 'Hi-net', so that we can compare the MT signals with the seismic wave records. During the MT observation period after the mainshock, some moderate-size aftershocks of magnitudes between 2.8 and 4.1 occurred and MT signals appeared in association with all these aftershocks. In order to confirm that MT signals are not due to vibrations of MT equipment, we set up two sets of MT equipment at the same location; in the case of electric field measurements, we used independent electrodes and arranged cables connecting electrodes on the ground for one set and in the air for the other set, and in the case of magnetic field measurements, we buried the induction coils under the ground for one set and hang them in the air for the other set. As for the electric field, the two sets showed exactly the same records. On the other hand, the magnetic field was different from one set to another, but we conclude that the induction coils buried in the ground are more likely to represent the magnetic field due to electric currents flowing in the ground as a result of the seismic dynamo effect.
\end{abstract}

Key words: Seismic dynamo effect, electric field, magnetic field, aftershock, Earth's magnetic field.

\section{Introduction}

Electric field variations associated with an earthquake have been one of the important topics for many years and it is only recently that some clear examples have been obtained, although they are not precursory but rather coseismic (Honkura et al., 2000; Mogi et al., 2000; Nagao et al., 2000; Matsushima et al., 2002; Honkura et al., 2002). Similar examples have also been obtained for quarry blasts (Yamada and Murakami, 1982). Similar variations have been found for the magnetic field (Iyemori et al., 1996; Honkura et al., 2000, 2002; Matsushima et al., 2002). In particular, Honkura et al. (2000, 2002) and Matsushima et al. (2002) clearly showed, with the magnetotelluric (MT) data obtained at a high sampling rate of $24 \mathrm{~Hz}$, that the onsets of electric and magnetic field variations are simultaneous with the arrivals of seismic waves with exceptions in the case of the 1999 Izmit earthquake, northwestern Turkey, in which the onset of MT signals was slightly earlier than the arrival of seismic wave (Honkura et al., 2002).

Honkura et al. (2000, 2002) and Matsushima et al. (2002) interpreted the MT field variations associated with seismic waves in terms of the seismic dynamo effect. In fact, it is

Copy right (C) The Society of Geomagnetism and Earth, Planetary and Space Sciences (SGEPSS); The Seismological Society of Japan; The Volcanological Society of Japan; The Geodetic Society of Japan; The Japanese Society for Planetary Sciences; TERRAPUB. quite natural to expect electric field variations arising from seismic waves, because the Earth's crust is conducting and when it vibrates with velocity $\boldsymbol{v}$ in the Earth's magnetic field $\boldsymbol{B}$, the electromotive force $\boldsymbol{v} \times \boldsymbol{B}$ is generated in the Earth, resulting in the flow of electric currents in the conducting crust. These currents in turn give rise to electric and magnetic fields at observation sites on the Earth's surface. In fact, slight signals observed before the arrival of seismic wave cannot be accounted for by simple vibration of the MT equipment.

Nonetheless, more convincing examples would be necessary to confirm the seismic dynamo effect. Also, more detailed discussion on whether the observed electric and magnetic signals are in fact due to the seismic dynamo effect would be necessary. In view of this, we made MT observations at a site in the epicentral area of the M7.1 earthquake which occurred on May 26, 2003, off Miyagi Prefecture, northeastern Japan. Although aftershocks were rather small during the observations period, we obtained many examples of electric and magnetic field variations which could be compared with seismic wave records at a nearby seismic station.

\section{MT Observation}

Figure 1 shows the location of the MT observation site in the epicentral region of the mainshock, indicated by a star symbol. We selected this site in order to compare the MT records with the seismic records obtained at the nearby 

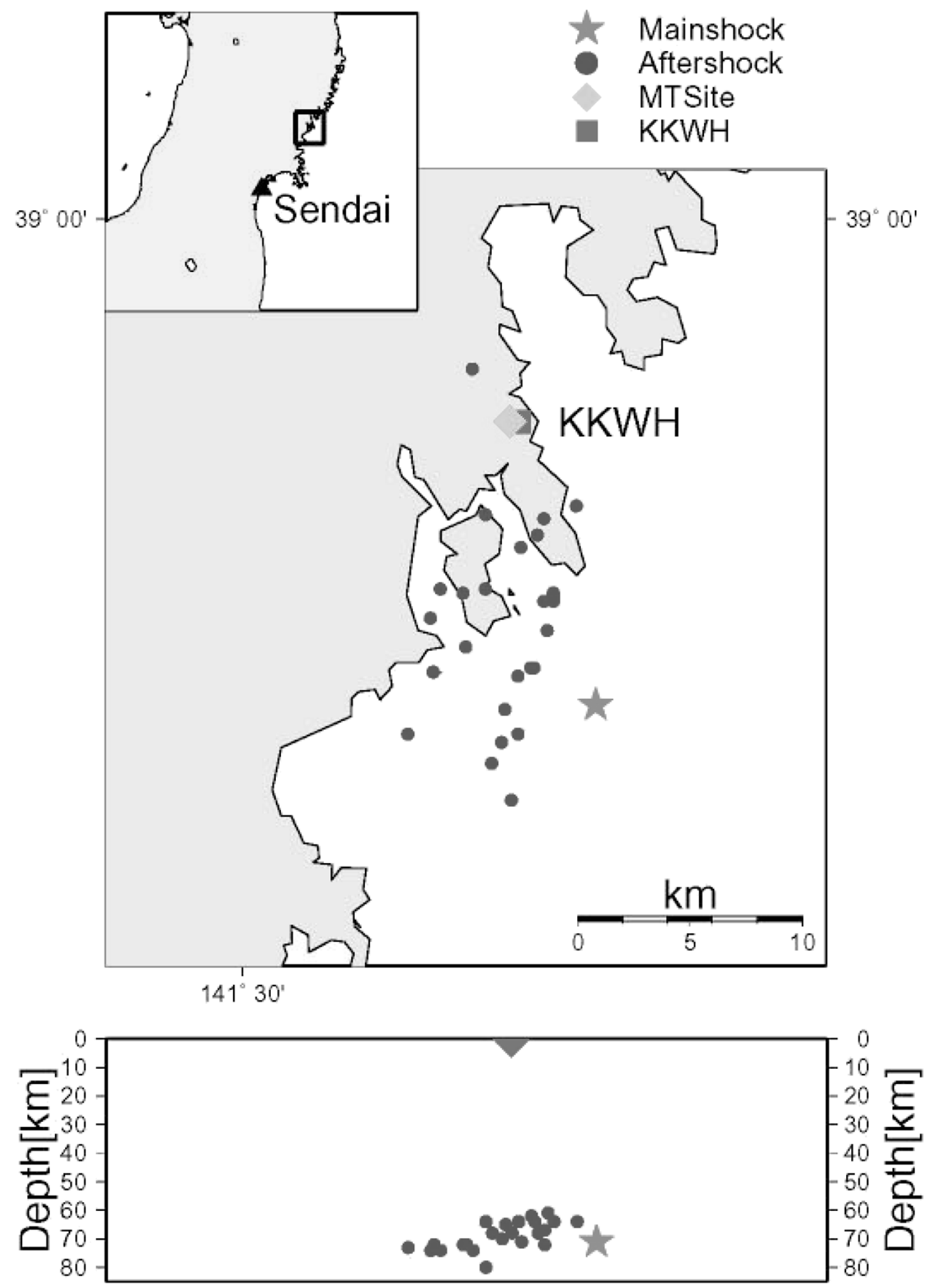

Fig. 1. Locations of the MT site and one of the Hi-net seismic stations, KKWH. A star symbol indicates the hypocenter of the off-Miyagi-Prefecture earthquake of 26 May 2003 and solid circles represent its aftershocks.

seismic station, denoted by KKWH, which is one of the nation-wide seismic observation network (Hi-net) stations. Aftershocks for which we could observe MT signals are also shown in this figure.

We used two sets of audio-frequency magnetotelluric equipment (AMT) which records horizontal electric and magnetic field components at a sampling rate of $150 \mathrm{~Hz}$. In order to verify that electric field variations are not due to the instrumental effects, we used independent sets of electrodes and also we designed a special arrangement for cables connecting electrodes, so that we can distinguish possible effects of vibrations of the cables from the seismic dynamo effect; we set cables on the ground for one set and in the air for the other set. Also for the magnetic field sensors (induction 


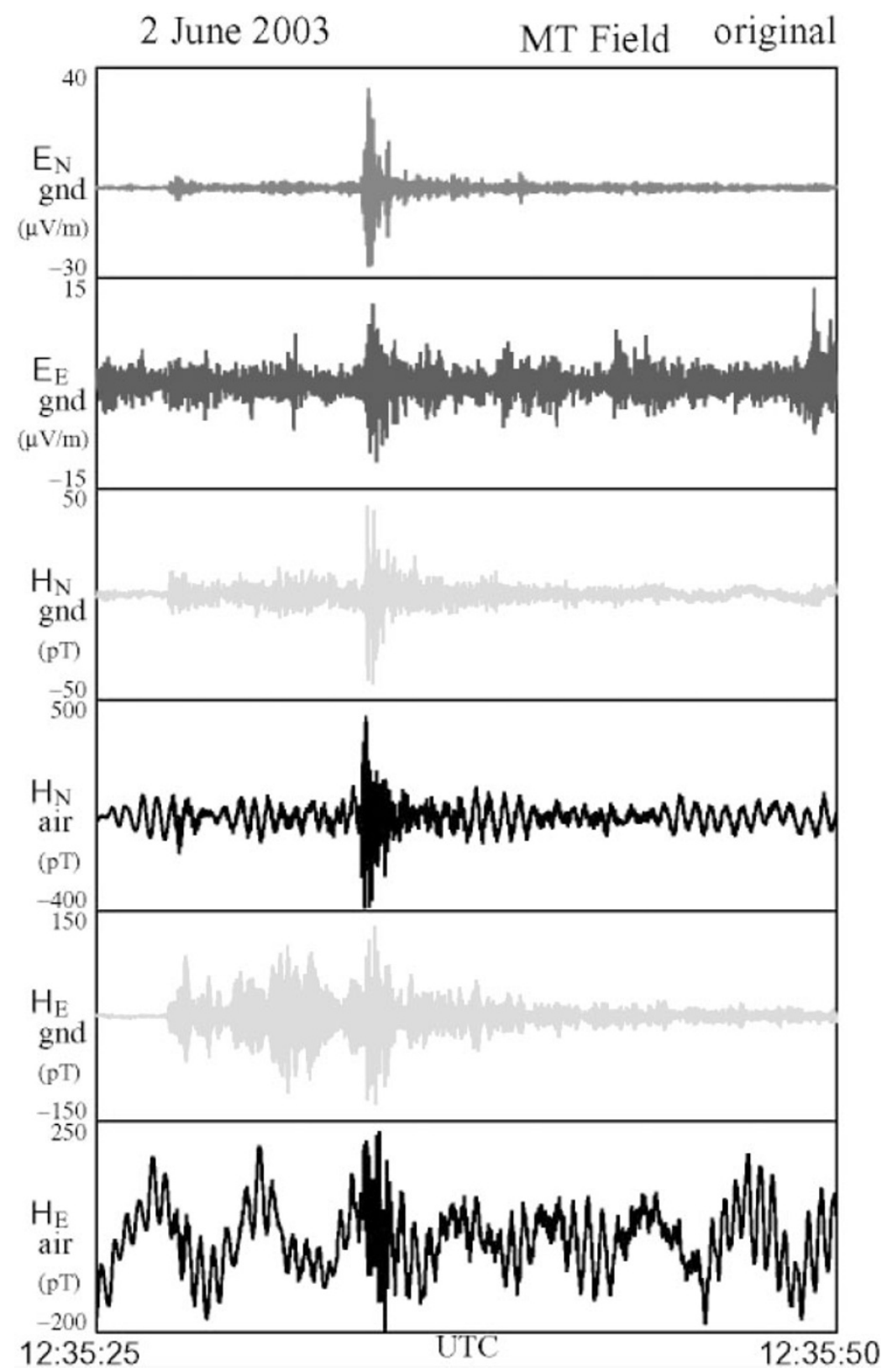

Fig. 2. One example of the electric $\left(E_{N}, E_{E}\right)$ and magnetic $\left(H_{N}, H_{E}\right)$ field records, where $N$ refers to the magnetic north and $E$ to the east. Two sets of magnetic sensors were used; one buried in the ground, as indicated by 'gnd' and the other hung in the air, as indicated by 'air'. Two independent sets of MT equipment were also used for the electric field, but the records were found to be exactly the same (see Fig. 3) and hence the records only for one set are shown here.

coils), we attempted two different types of magnetic sensor set-up. For one set, we buried the sensors in the ground as we usually do for MT measurements to avoid vibration due to wind. For the other set, we hang the sensors in the air between trees. This arrangement should by no means be used in MT and in fact large variations were observed because of oscillations of sensors. The reason why we adopted this arrangement is simply to force the sensors to move with the frequency response different from the ground movement during seismic wave passage, just like the principle of seismometer itself.

\section{Observed Data}

Figure 2 shows the original records for the northward $\left(E_{N}\right)$ and eastward $\left(E_{E}\right)$ electric field components, and for the two sets of the northward $\left(H_{N}\right)$ and eastward $\left(H_{E}\right)$ magnetic field components. In the case of the electric field, two sets of records turned out to be the same (see Fig. 3) and so here only one set is shown. This clearly indicates that the observed electric field is not a simple cable effect, but reflects the electric field flowing in the ground. In fact, if we compare the $E_{x}$ and $E_{y}$ records with the seismic records at the KKWH Hi-net station, shown in Fig. 4, we can see good correspondence between them, which confirms that the electric fields are generated by the seismic dynamo effect. The seismic wave seems to have arrived a little bit earlier than the electric and magnetic signals, but this is due to different locations for the seismometer and MT equipment; the former is located at the bottom of a bore hole at the depth of $117 \mathrm{~m}$, and the latter at the location $50 \mathrm{~m}$ higher than the seismic sta- 


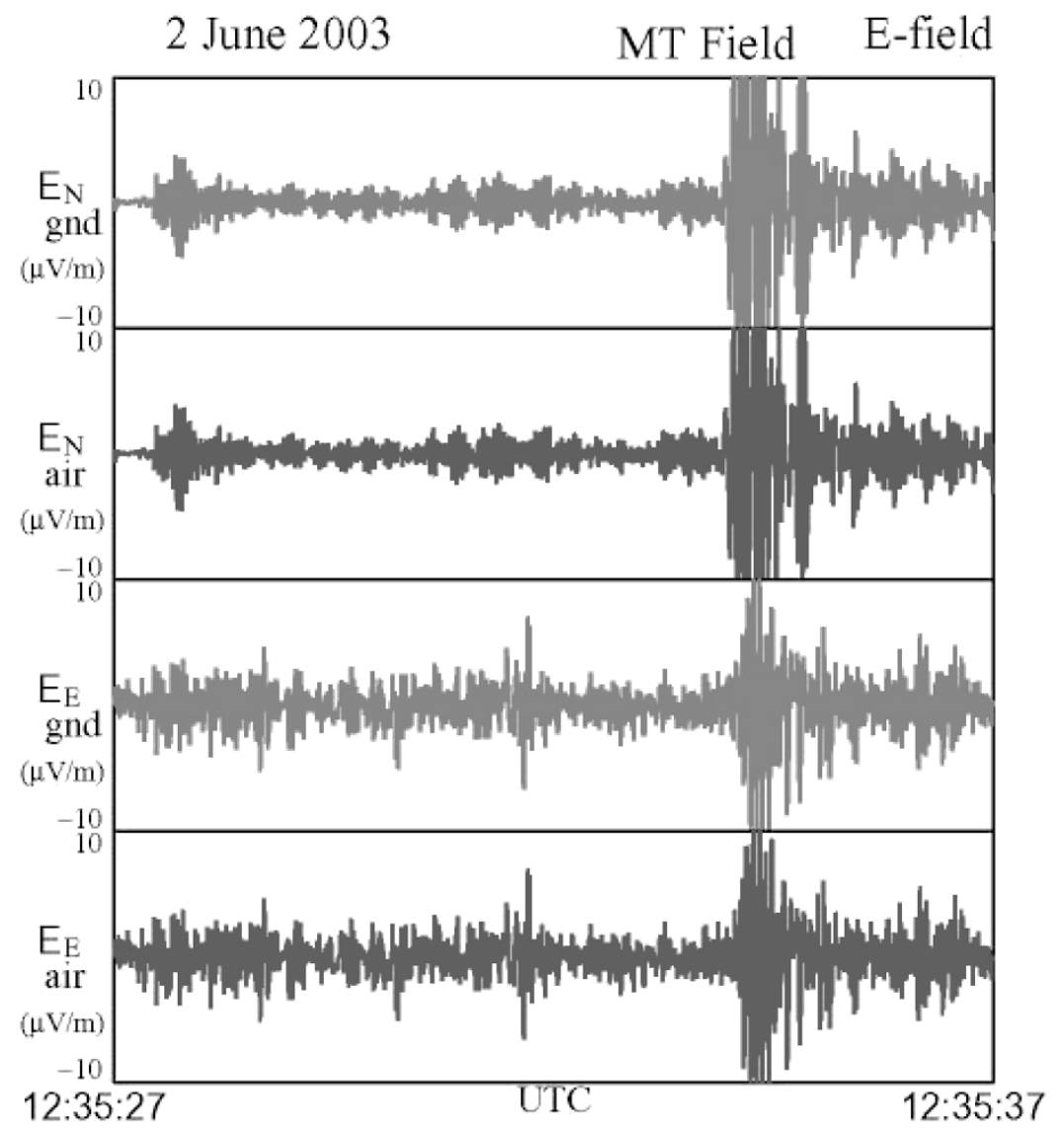

Fig. 3. Two independent sets of the electric field records. For one set, cables connecting the electrodes were hung in the air, as indicated by 'air', and for the other, they were placed on the ground surface, as indicated by 'gnd'.

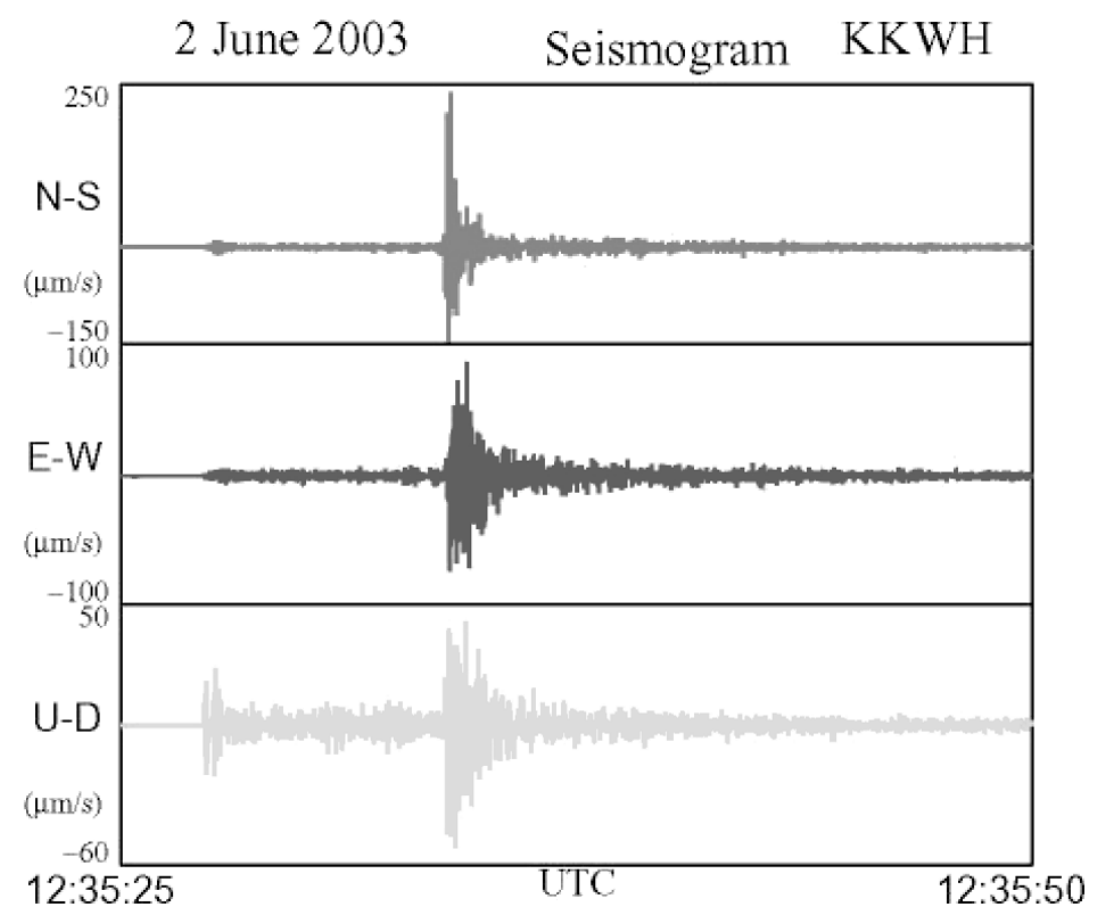

Fig. 4. The N-S, E-W and U-D components of ground velocity at KKWH, one of the Hi-net stations, which correspond to the electric and magnetic fields shown in Fig. 2. 


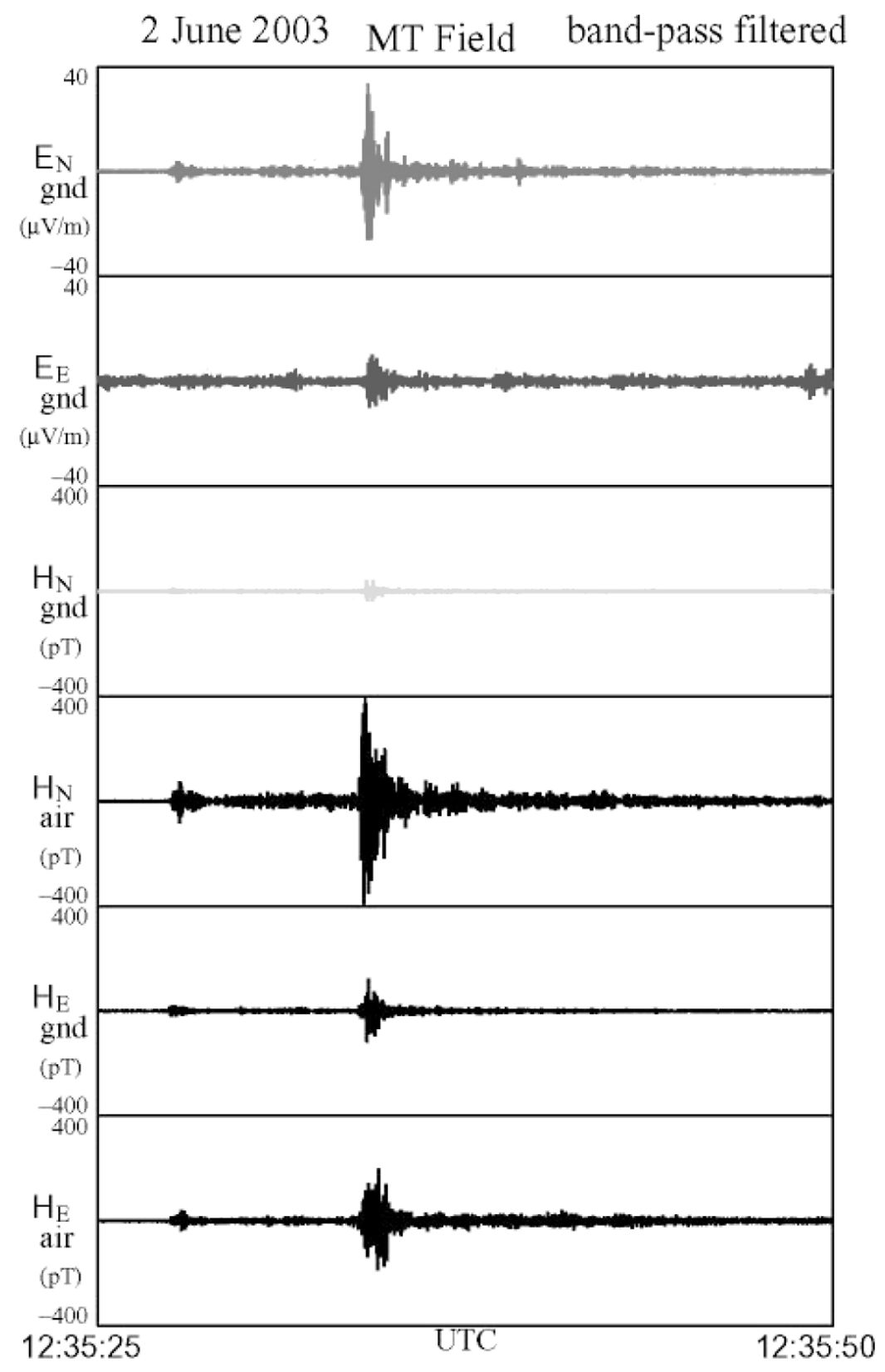

Fig. 5. Electric and magnetic field records after band-pass filtering operation for the records shown in Fig. 2. The pass band is between 8 and $35 \mathrm{~Hz}$.

tion. Also the horizontal distance between the two is about $300 \mathrm{~m}$.

On the other hand, two sets of magnetic field records clearly show different responses. In the records for the set-up in the air, low frequency oscillations are evident, but superposed on the oscillations, higher frequency components are also seen particularly during the arrival of $S$ wave. The low frequency oscillations can be removed through band-pass filtering with the pass band between 8 and $35 \mathrm{~Hz}$, as shown in Fig. 5, and now we see good correspondence between Figs. 4 and 5. The same filtering was also performed to the seismic records for comparison. During this operation we found some high-frequency noises of probably instrumental origin in $H_{E}$ (ground), but they are also filtered out.

It should be noted in Fig. 5, however, that the records for the magnetic sensors hung in the air are not the same as those for the magnetic sensors buried in the ground. We can reasonably interpret these differences as follows. The output of an induction coil is given by

$$
d \boldsymbol{B} / \mathrm{dt}=\partial \boldsymbol{B} / \partial \mathrm{t}+(\boldsymbol{v} \cdot \operatorname{grad}) \boldsymbol{B}_{0},
$$

where $\boldsymbol{v}$ represents the ground velocity and $\boldsymbol{B}_{0}$ the static magnetic field at the sensor location. The first term on the right-hand-side is the time variation of the magnetic field and the second term the effect of movement of the sensor in the magnetic field $\boldsymbol{B}_{0}$. In the present case, the former represents the magnetic field generated by electric currents flowing in the crust. The magnetic sensors buried in the ground are supposed to move with the ground and hence the electromotive force will be generated in the induction coil by the second term in proportion to the gradient of the Earth's magnetic field, the order of which is $10^{-3} \mathrm{nT} / \mathrm{m}$. If the sensors are hung in the air and free from the ground motion, we expect no contribution from the Earth's magnetic 

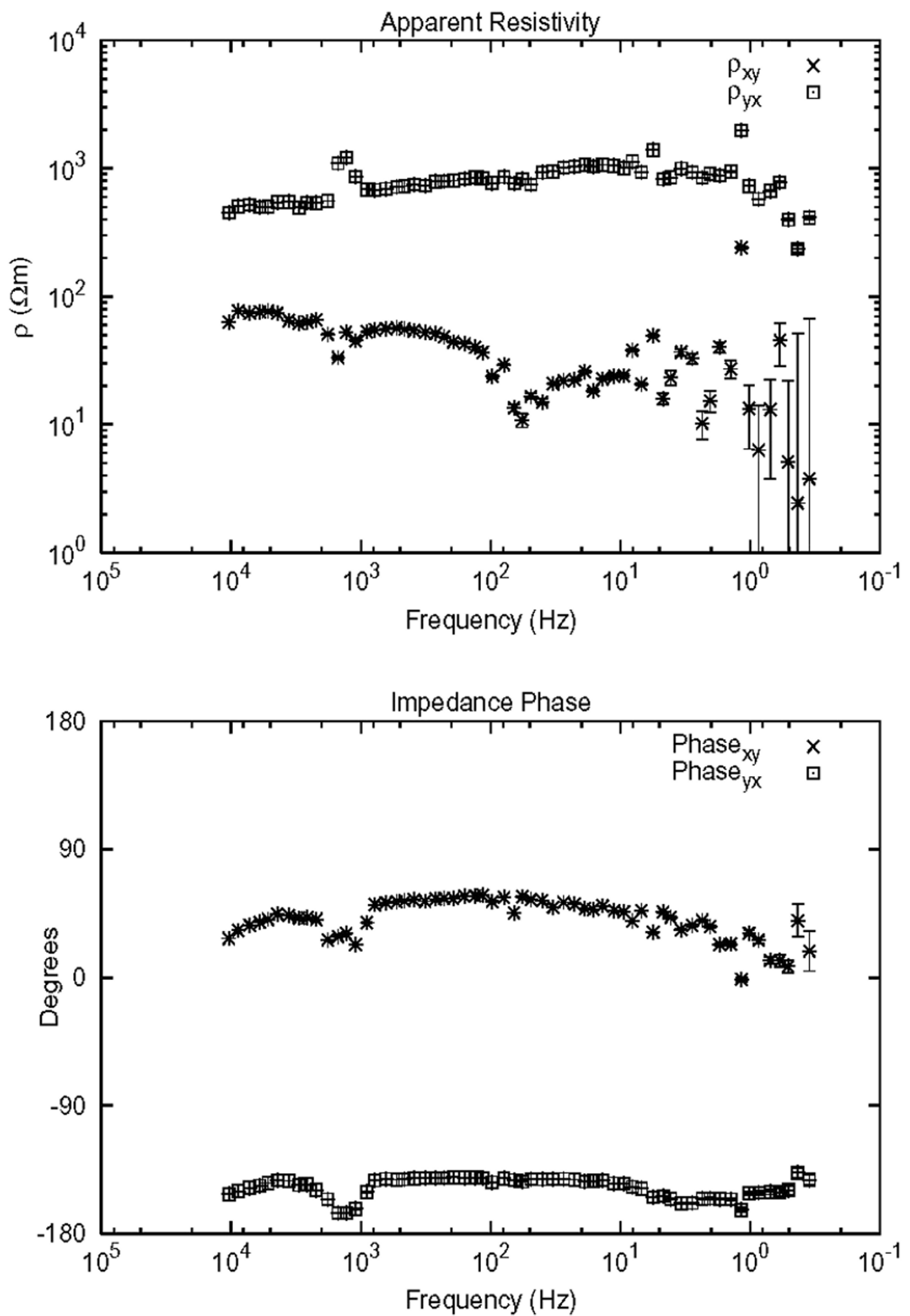

Fig. 6. Apparent resistivity and phase curves derived from the MT data which do not include variations due to the seismic dynamo effect. The shift of apparent resistivity curves for two modes, $\rho_{x y}$ and $\rho_{y x}$, represent anisotropic response of the electric field. Here $x$ corresponds to $\mathrm{N}$ and $y$ to E.

field, but in this case the local magnetic field, due to crustal magnetization, moves relative to the sensors. In other words, the sensors move, oppositely to the ground, in the presence of the static local magnetic field. Its gradient is typically the order of $1 \mathrm{nT} / \mathrm{m}$. In total, there are three components with one common component.
As clearly understood from the above argument about the gradient of the static magnetic field, the output of the air sensors should be much larger than that of the ground sensors, if the common component representing the magnetic field due to electric currents flowing in the crust is negligible. But this is not the case. In fact, both are of the same order (Fig. 5). 

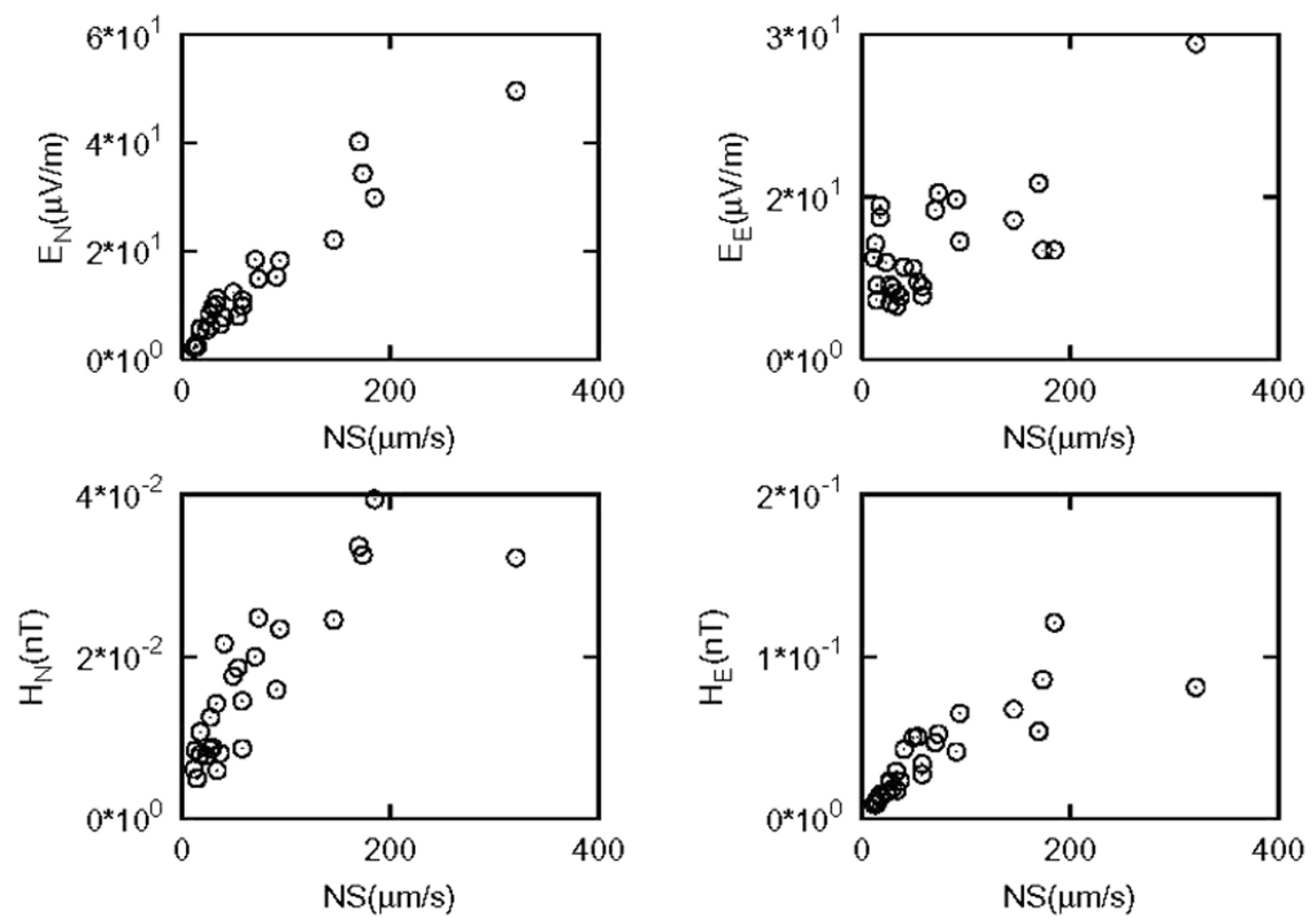

Fig. 7. Relation between the N-S component of the ground velocity and each component of electric $\left(E_{N}, E_{E}\right)$ and magnetic $\left(H_{N}, H_{E}\right)$ fields.
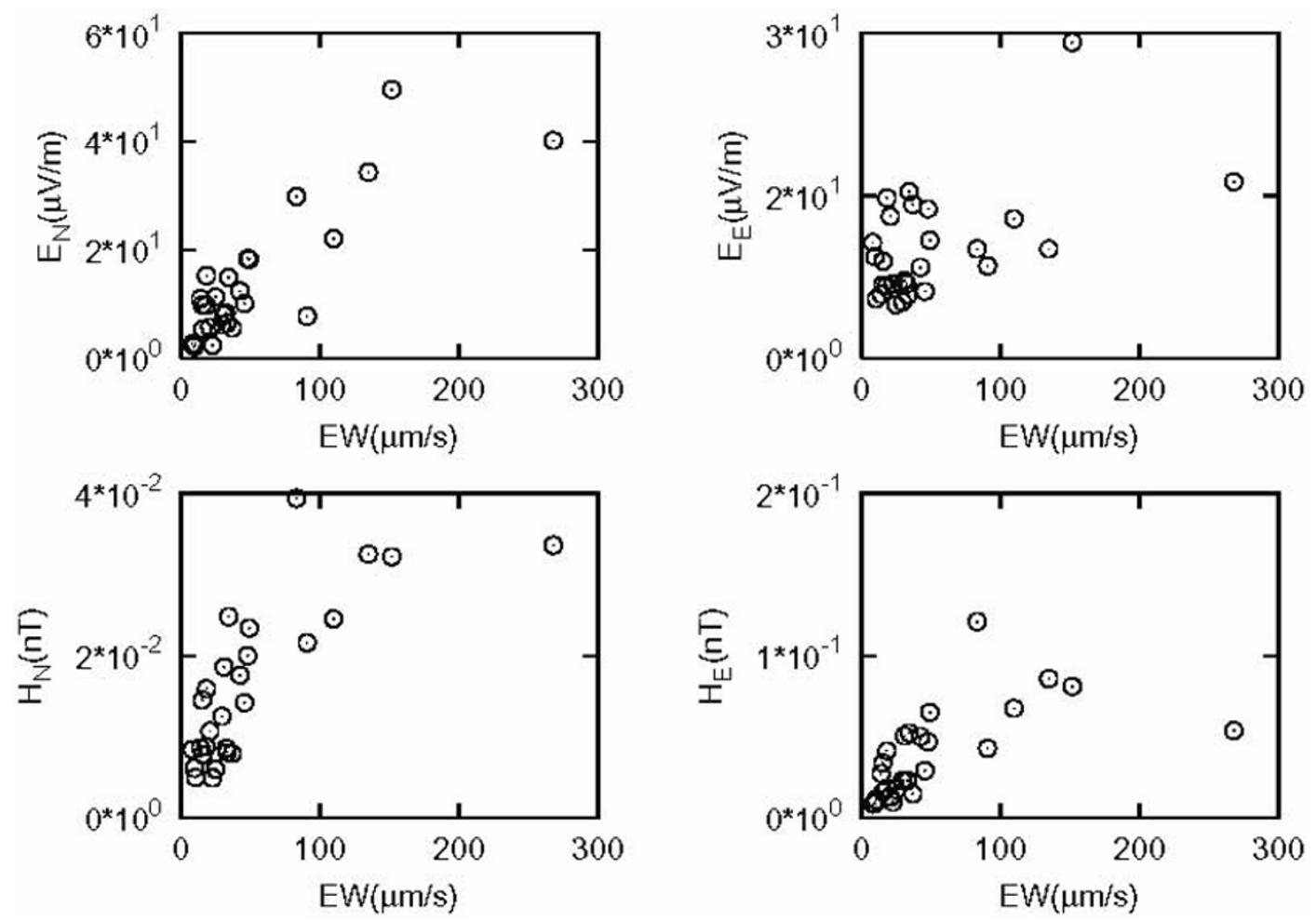

Fig. 8. Relation between the E-W component of the ground velocity and each component of electric $\left(E_{N}, E_{E}\right)$ and magnetic $\left(H_{N}, H_{E}\right)$ fields.

Hence the second term for the ground sensors should be very small and we may regard the output of the ground sensors as representing the magnetic field due to the dynamo effect.

This conclusion is also supported by the following characteristics. As seen in Fig. 5, $E_{N}$ is about three times larger than $E_{E}$. The apparent resistivity estimates, which were determined for the MT records not including the signals associated with seismic waves, also show apparent anisotropy, as shown in Fig. 6. Such anisotropy in the electric field is obviously due to different response in electromagnetic induc- 

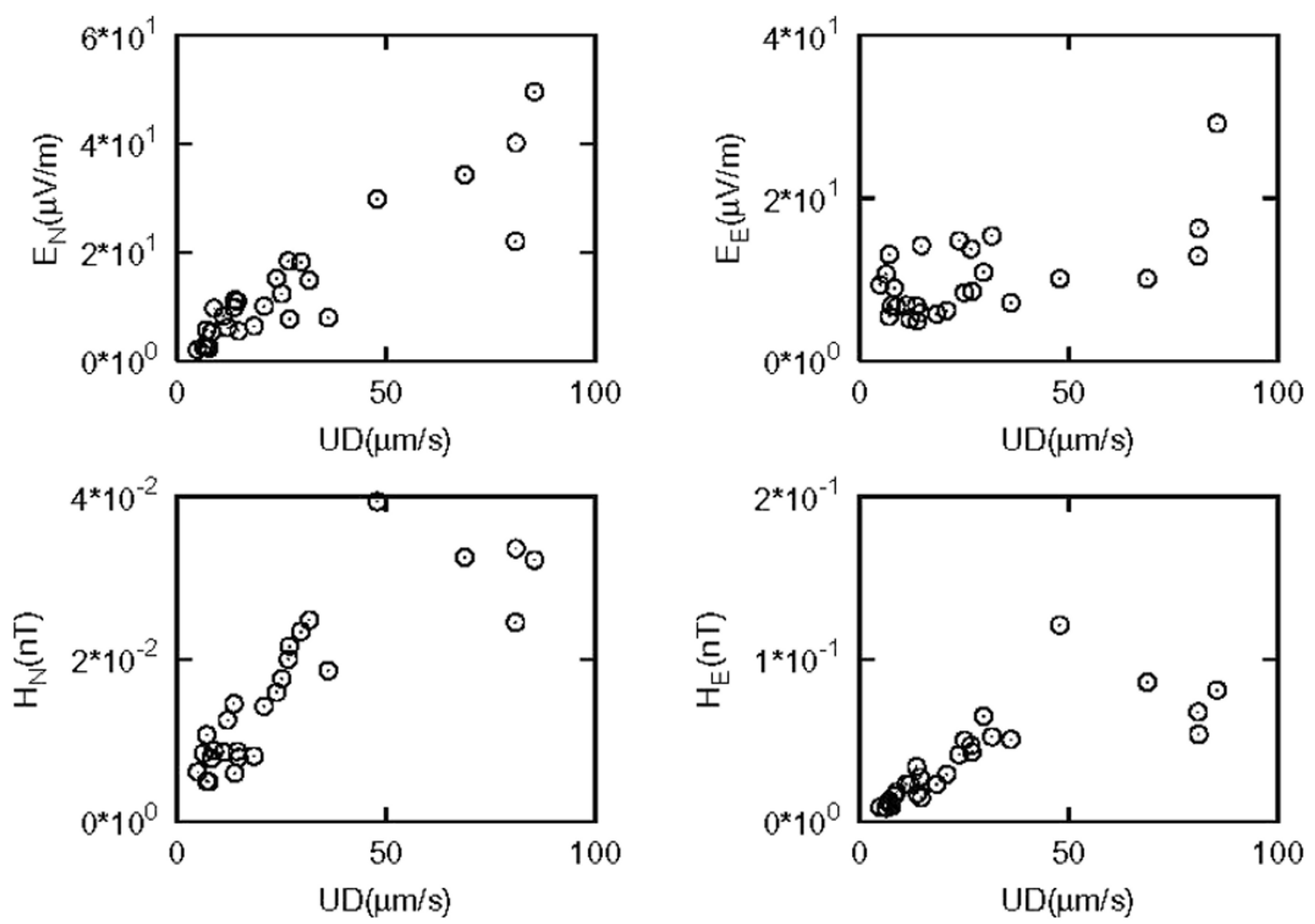

Fig. 9. Relation between the U-D component of the ground velocity and each component of electric $\left(E_{N}, E_{E}\right)$ and magnetic $\left(H_{N}, H_{E}\right)$ fields.

tion for different polarity of the inducing magnetic field. The seismic dynamo effect is also an electromagnetic induction process in the crust and hence affected by such anisotropic response. In the case of the seismic dynamo effect, the magnetic field at the Earth's surface is due to electric currents flowing in the crust, and hence $H_{N}$ should correspond to $E_{E}$ and $H_{E}$ to $E_{N}$ at least approximately. Then $H_{E}$ is expected to be about three times larger than $H_{N}$. In fact, Figure 5 shows such a relation.

\section{Statistical Argument}

During the observation period, we could detect MT signals for 27 aftershocks with magnitudes ranging between 2.8 and 4.1. In this section, we show relations between the electric and magnetic signals with the ground velocity data obtained at the KKWH station. Figure 7 shows the relation between the peak amplitudes of each component of the electric and the magnetic fields with the peak amplitude of the north-south component of the ground velocity. Except for $E_{E}$, which is rather noisy as can be seen in Fig. 2, a linear relation is well recognized. This is well explained by the electromotive force $\boldsymbol{v} \times \boldsymbol{B}$ in the seismic dynamo effect. Similarly, Figures 8 and 9 show the relation between each component of the electric and the magnetic fields with the east-west and the up-down components of ground velocity, respectively. We can see similar characteristics. We notice a strange trend for the higher velocity range. In fact, some magnetic data are smaller than those expected for the velocity through a linear trend. We obviously need more data, particularly for a wider velocity range, to investigate whether this trend is real and reflects a physical mechanism.

\section{Conclusions}

Through the MT data obtained for aftershocks of the M7.1 earthquake which occurred off Miyagi Prefecture on 26 May 2003, we obtained the following conclusions.

(1) The electric field variations observed during seismic wave passage are not due to a simple cable effect but reflects the field generated by the electromotive force due to the seismic dynamo effect.

(2) The magnetic field observed with the magnetic sensor of induction coil type buried in the ground includes both the instrumental effect and the field generated by electric currents flowing in the ground. However, the instrumental effect is much smaller than the magnetic field due to these electric currents. Hence the magnetic field observed with the sensors buried in the ground can be regarded as representing the magnetic filed due to the seismic dynamo effect.

(3) The present results confirm, observationally though, our claim that the mechanism of seismic dynamo effect is responsible for the electric and magnetic field variations associated with the seismic wave.

Acknowledgments. We used the seismic data obtained at one of the Hi-net stations, KKWH, in Miyagi Prefecture. We are thankful to the data center of the Disaster Prevention Research Institute. We thank Malcolm Johnston and Jacques Zlotnicki for valuable comments which were extremely useful in clarifying the argument.

\section{References}

Honkura, Y., A. M. Işikara, N. Oshiman, A. Ito, B. Üçer, Ş. Bariş, M. K. Tunçer, M. Matsushima, R. Pektaş, C. Çelik, S. B. Tank, F. Takahashi, M. Nakanishi, R. Yoshimura, Y. Ikeda, and T. Komut, Preliminary results of multidisciplinary observations before, during and after the Kocaeli 
(Izmit) earthquake in the western part of the North Anatolian Fault Zone, Earth Planets Space, 52, 293-298, 2000.

Honkura, Y., M. Matsushima, N. Oshiman, M. K. Tunçer, Ş. Bariş, A. Ito, Y. Iio, and A. M. Işikara, Small electric and magnetic signals observed before the arrival of seismic wave, Earth Planets Space, 54, e9-e12, 2002.

Iyemori, T., T. Kamei, Y. Tanaka, M. Takeda, T. Hashimoto, T. Araki, T. Okamoto, K. Watanabe, N. Sumitomo, and N. Oshiman, Co-seismic geomagnetic variations observed at the 1995 Hyogoken-nanbu earthquake, J. Geomag. Geoelectr., 48, 1059-1070, 1996.

Matsushima, M., Y. Honkura, N. Oshiman, S. Baris, M. K. Tuncer, S. B. Tank, C. Cerik, F. Takahashi, M. Nakanishi, R. Yoshimura, R. Pektas, T. Komut, E. Tolak, A. Ito, Y. Iio, and A. M. Isikara, Seimoelecromagnetic effect associated with the Izmit earthquake and its aftershocks, Bull. Seismol. Soc. Am., 92, 350-360, 2002.
Mogi, T., Y. Tanaka, D. S. Widarto, E. M. Arsadi, N. T. Puspito, T. Nagao, W. Kanda, and S. Uyeda, Geoelectric potential difference monitoring in southern Sumatra, Indonesia-Co-seismic change-, Earth Planets Space, 52, 245-252, 2000.

Nagao, T., Y. Orihara, T. Yamaguchi, I. Takahashi, K. Hattori, Y. Noda, K. Sayanagi, and S. Uyeda, Co-seismic geoelectric potential changes observed in Japan, Geophys. Res. Lett., 27, 1535-1538, 2000.

Yamada, I. and H. Murakami, Self-potential variations associated with quarry blasts, Zisin, 35, 393-400, 1982 (in Japanese with English abstract).

N. Ujihara (e-mail: nujihara@geo.titech.ac.jp), Y. Honkura (e-mail: yhonkura@geo.titech.ac.jp), and Y. Ogawa (e-mail: oga@ksvo.titech.ac.jp) 